\title{
A Brief Overview of Preeclampsia
}

\author{
Noura Al-Jameil ${ }^{\mathrm{a}, \mathrm{b}}$, Farah Aziz Khan ${ }^{\mathrm{a}}$, Mohammad Fareed Khan ${ }^{\mathrm{a}}$, \\ Hajera Tabassum ${ }^{\text {a }}$
}

\begin{abstract}
Preeclampsia (PE) is a leading cause of maternal mortality and morbidity worldwide. It occurs in women with first or multiple pregnancies and is characterized by new onset hypertension and proteinuria. Improper placentation is mainly responsible for the disease. If PE remains untreated, it moves towards more serious condition known as eclampsia. Hypertension, diabetes mellitus, proteinuria, obesity, family history, nulliparity, multiple pregnancies and thrombotic vascular disease contribute as the risk factors for PE. PE triggered metabolic stress causes vascular injury, thus contributing to the development of cardiovascular disease (CVD) and/or chronic kidney disease (CKD) in future. This risk appears to be increased especially in women with a history of recurrent PE and eclampsia. Clinically increased serum levels of sFlt-1 and decreased placental growth factor (PIGF) and vascular endothelial growth factor (VEGF) represent the severe condition of PE. The clinical findings of sever PE are assorted by the presence of systemic endothelial dysfunction, microangiopathy, the liver (hemolysis, elevated liver function tests and low platelet count, namely HELLP syndrome) and the kidney (proteinuria). The early detection of PE is one of the most important goals in obstetrics.
\end{abstract}

Keyword: Preeclampsia; Eclampsia; Hypertension; Proteinuria; Microangiopathy

\section{Introduction}

Preeclampsia (PE) is a most frequently encountered renal complication of pregnancy and it is characterized by hyper-

\footnotetext{
Manuscript accepted for publication November 27, 2013

${ }^{a}$ Department of Clinical Laboratory Sciences, College of Applied Medical Sciences, King Saud University, Riyadh, Kingdom of Saudi Arabia

${ }^{\mathrm{b}}$ Corresponding author: Noura Al-Jameil, Department of Clinical Laboratory Sciences, College of Applied Medical Sciences, King Saud University, Riyadh, Kingdom of Saudi Arabia.

Email: nouraaljameil@gmail.com
}

doi: http://dx.doi.org/10.4021/jocmr1682w tension, proteinuria and edema, usually by the last trimester of pregnancy. The rate of incidence varies upon the study population but generally ranges from $3 \%$ to $7 \%$ of all pregnancies [1-4]. It occurs manly in the women in their first pregnancies or to those who carry twins [5]. PE when remains untreated, it moves towards more serious condition known as eclampsia, and is still one of the leading causes of maternal and neonatal mortality. It takes place only in the presence of placenta even without fetus (hydatidiform mole), and typically improves postpartum [6, 7]. Hypoperfusion and ischemic conditions evidently show the abnormal placenta. PE is known to be originated from disordered vascular development of the placenta which further widely spreads anti-angiogenic factors into the maternal circulation and causes a systemic endothelial cell dysfunction and microangiopathy $[8,9]$. Upon kidneys these endothelial damages result in glomerular endotheliosis and proteinuria in which the endothelial cells of the glomerulus swell and endothelial fenestrations are lost $[1,10]$.

As mentioned above, the untreated complication of PE is eclampsia. It is defined by the presence of seizures for which women are often treated with magnesium sulfate prophylaxis [11]. The clinical findings of sever PE are assorted by the presence of systemic endothelial dysfunction and microangiopathy, the liver (hemolysis, elevated liver function tests and low platelet count, namely HELLP syndrome) and the kidney (proteinuria) [12].

\section{Risk Factors and Pathogenesis of Preeclamp- sia}

$\mathrm{PE}$ is a disorder of pregnancy which affects various organs. Hypertension, diabetes mellitus, proteinuria, obesity, family history, nulliparity, multiple pregnancies, use of contraceptions, older women conception $(>40)$ and thrombotic vascular disease contribute as the risk factors for PE [13, 14]. New onset of hypertension (systolic $\geq 140 \mathrm{mmHg}$ in $24 \mathrm{~h}$ urine) can be seen after 20 weeks of gestation in previously normal women. Several other symptoms like edema, renal failure, liver failure and HELLP syndrome also worsen the clinical condition [15]. Depending upon the early or late on- 
set, disease can show mild or severe symptoms. Deranged liver function, thrombocytopenia and HELLP syndrome can evolve in eclampsia in severe cases $[16,17]$.

Nulliparous women (who conceived through assisted reproductive techniques) and women already affected by autoimmune disease can experience disturbed maternal immune system in the early onset $[18,19]$. On the contrary, women with metabolic, renal or vascular disease are especially at increased risk for superimposed PE. Environmental factors may also contribute to the disease for those who are living at higher altitude and facing hypoxic conditions [20].

In a study, Cunningham et al evaluated 37 pregnant women and reported $58 \%$ and $64 \%$ PE in subjects with moderate and severe renal insufficiency respectively [21]. On the contrary, Fink et al observed a ratio of 7.3 for PE in 169 women with renal disease [22]. The histopathological origin widely differs but diabetic nephropathy is known to be the most common cause of chronic kidney disease (CKD) in pregnancy [22].

The abnormal placenta is known to be the major cause for the origin of PE, and its removal puts an end to the disease. Due to abnormal implantation and placentation poor uterine and placental perfusion occurs which leads to oxidative stress, hypoxic condition and release of some anti-angiogenic factors [23]. These anti-angiogenic factors lead to generalized endothelial dysfunction which is responsible for hypertensive syndrome and microangiopathy [23]. Pathological examination of placentas from women with severe PE reveals several abnormalities like infarcts, thrombosis, atherosis and chronic inflammation [24]. Some anti-angiogenic proteins produced by abnormal placenta are soluble endoglin (sEng) and the soluble vascular endothelial growth receptor-1 (sFlt-1), which induce endothelial dysfunction by inhibiting pro-angiogenic factors like placental growth factor (PIGF) and vascular endothelial growth factor (VEGF) [2528]. Maternal blood levels of sFlt-1 represent the severity of PE whereas oppositely quantities of VEGF and PIGF were decreased in patients with severe symptoms when compared to normal pregnancies. Alterations in sFlt-1 and PIGF are also more pronounced in early onset in comparison to late onset PE [29]. Before going to discuss the role of anti-angiogenic factors, we put a light over the role of pro-angiogenic growth factors and their receptors in vascular homeostasis.

\section{Pro-angiogenic factors}

VEGFs are dimeric glycoproteins involved in angiogenesis and vasculogenesis [30]. VEGF family receptors present on vascular endothelial cells include Flt-1 (VEGFR-1) and KDR (VEGFR-2). VEGFs are known to bind with both kinds of receptors, namely Flt-1 and KDR, while PIGF homodimers bind specifically to Flt-1. VEGFs mainly act upon VEGFR-2 to affect endothelial cells [31]. Chappel et al suggest that the role of Flt-1 gene to express sFlt-1 which acts by regulating guidance of emerging vessel sprouts by modulating local VEGF availability [32]. The extirpation of single VEGF allele results in markedly abnormal vasculature inkling the placental vasculature with death at embryonic days 10-12 [33]. The survival of endothelial cells and vascular homeostasis in mature vessels and tissues is because of VEGF. Cells responsible for VEGF expression are located adjacent to fenestrated endothelia, epithelial cells of the choroid plexus, renal podocytes and hepatocytes [34, 35]. The inhibition of VEGF leads to pathological conditions in many of the organs with fenestrated endothelia and it is also observed in PE. VEGFs have a direct vasodilatory effect on the systemic vasculature because infusion of VEGF leads to nitric oxidedependent vasorelaxation in the coronary artery [36].

PIGF shows similarity to VEGF and expresses at high levels from placenta. As mentioned earlier, it binds with Flt-1 receptor with high affinity. In an animal study PIGF null mice exhibit defects in tumor angiogenesis, myocardial neovascularization and wound healing suggesting that PIGF plays a role in angiogenesis in pathological settings [37]. PIGF binds itself more actively with Flt-1 receptor by displacing VEGF from Flt-1; other possible mechanisms include direct effects of Flt-1 signaling and the formation of VEGF/PIGF heterodimers. During pregnancy placenta releases high quantity of PIGF and their levels increase from second trimester and thereafter decline [38].

\section{Anti-angiogenic factors}

Various studies have potentially established the presence of factors in the circulation of preeclamptic women released by injured or activated endothelium. Among other these factors include endothelin-1, fibronectin, von Willebrand factor, oxidative stress markers, thrombomodulin and inflammatory cytokines [39]. There is a deficiency of prostacyclin, nitric oxide, vasodilatory factors in the circulation of women with PE [40]. A theory, that circulating factors cause the endothelial dysfunction, was strengthened when in vitro serum from women with preeclampsia induces endothelial dysfunction and injury [41].

Anti-angiogenic factors release from the placenta and enter into maternal circulation, which is the main cause of endothelial dysfunction in PE. An anti-angiogenic protein, soluble fms-like tyrosine kinase (sFlt-1, also known as sVEGFR-1) is a soluble form of VEGF/PIGF receptor Flt-1 produced by alternative splicing [42]. sFlt-1 inhibits VEGF and PIGF activity by halting endothelial tube formation and blocking their vasodilatory effect. In an animal study administration of sFlt-1 to pregnant rats induces hypertension, proteinuria and glomerular endotheliosis [43].

Another anti-angiogenic factor is sEng found from placentas of women with PE. Studies have identified sEng levels 4-fold higher in females with severe PE than normal women. sEng when combined with sFlt-1 induces features of 
sever PE like liver dysfunction, restricted fetal growth, coagulation and neurological abnormalities [44, 45]. In an animal study, sEng stricts the formation of endothelial tube and increases capillary permeability in mouse, liver, lung and kidney. When pregnant rats were dozed with combined sFlt-1 and sEng marked features of PE were developed, namely hypertension, nephrotic syndrome, low platelet count, elevated liver enzymes and reduced fetal weight [44].

\section{Pathophysiology of Various Clinical Instances}

\section{Hypertension}

Hypertension is very commonly seen in PE. Increased peripheral vascular resistance rather than increased cardiac output is the cause of hypertension [46]. PE exaggerates response to angiotensin II, catecholamines and other hypertensive stimuli when compared to normal controls [47]. A study has reported that the effect may elevate the onset of overt hypertension by weeks to months [48]. In PE total plasma volume gets low [49] and probably increases circulating volume as evidenced by suppressed rennin and aldosterone [ 50 , 51] and elevated natriuretic hormone compared to normal pregnancy [52]. The markers of endothelial activation and dysfunction like endothelin, cellular fibronectin, plasminogen activator inhibitor-1 (PAI-1) and von Willebrands factor are altered in PE. In in vitro studies altered endothelial functions have been observed in preeclamptic vessels $[53,54]$. The increased incidence of PE in women with chronic diseases like diabetes and hypertension suggests some factor in maternal milieu may also lend susceptibility to PE. Several mediators like vasoconstrictors norepinephrine, endothelin, thromboxane and vasodilators prostacyclins and nitric oxide are known to mediate vasoconstriction.

\section{Cardiovascular risk}

PE can proceed to permanent vascular, metabolic damage and also elevate the risk of cardiovascular disease (CVD). A study showed increased relative risk of CVD after PE [55]. CVD is known to be the major cause of mortality worldwide [53]. In a study insulin resistance and angiogenesis dysfunction revealed the association between PE and metabolic syndrome which showed even one year after delivery serum glucose and sFlt-1 continuously increase [56]. It is noted that increased rates of CVD and type 2 diabetes were observed in gestational hypertension. Large retrospective epidemiological studies have consistently demonstrated elevated risk for many types of CVD in women with history of PE. CVD and $\mathrm{PE}$ have some common risk factors like obesity and metabolic syndrome. Therefore as PE is known to be the risk factor for CVD, CVD does the same with PE [57-61]. Women had PE before 34 weeks or PE combined with preterm birth has an even higher risk of death from CVD, at four to eight times the risk of women who had a normal pregnancy [62].

Persons born to pregnancies complicated by PE or gestational hypertension may also have some future cardiovascular risks. Increased risk of hemorrhage and ischemic stroke after the stages of 60 - 70 years was reported, mainly among those with the history of severe PE, maybe due to cerebral vascular dysfunction brought about by development failure during intrauterine life [63-65].

\section{Hyperuricemia}

More than 80 years before the relation between serum uric acid and PE has been established [66]. Serum uric acid levels are proportional in women with $\mathrm{PE}$, severity of proteinuria, renal changes, maternal morbidity and fetal demise $[67,68]$. In a recent study, it has been suggested that hyperuricimea directly contributes to vascular damage and hypertension [69].

\section{Neurological abnormalities}

If $\mathrm{PE}$ remains untreated, the condition is complicated by the development of seizures in brain and is referred as eclampsia. Headache, blurred vision and temporary loss of vision are few symptoms of eclampsia. The neurological changes like cerebral edema and vasoconstriction have been attributed in PE. The cerebral edema involves the posterior portions of the white matter and known as reversible posterior leuko encephalopathy syndrome (RPLS) [70, 71].

\section{Renal Effects of Preeclampsia}

The kidneys are among the main organs affected by PE and result can be seen in the form of proteinuria. The level of proteinuria is directly related to poor maternal and prenatal prognosis and higher risk of complications like eclampsia and HELLP syndrome. The urine protein to creatinine ratio ( $\mathrm{P}: \mathrm{C}$ ratio) has become the preferred method to quantify proteinuria in non-pregnant population but it is still controversial in the diagnosis of PE $[72,73]$. Microalbuminuria is a marker of renal endothelial injury resulting from local or systemic vascular damage. There is an increased risk of persistent microalbuminuria after PE and this may be the main cause of kidney disease after PE [74, 75]. In a study who previously encountered PE have increased risk of later end stage renal disease, and women with recurrent preeclamptic pregnancies and who give birth to offspring with low birth weight had even high risk. Many mechanisms explain the association between PE and renal disease. Hypertension, endothelial dysfunction, obesity and CVD are the risk factors for chronic kidney disease and PE seems to be related four to five times higher related risk with CKD and microalbumin- 
uria [76, 77].

The glomerular consequences of PE can be understood in terms of disruption of glomerular filtration barrier (GFB) through glomerular endothelial cell injury. Not only endothelial damage results in endotheliosis, the podocytes are simultaneously disrupted, since these specialized cells are highly dependent on signals derived from glomerular endothelial cells to maintain structures and the diaphragms [78]. Glomerular endothelial cell injury causes the breakdown of multiple components of GFB which leads to proteinuria and hypertension. Arteriolar endothelial injury also occurs in PE and may induce narrowing of arteriolar lumina. Thus, glomerular filtration is compromised and manifests as elevated blood pressure [79].

The decreased GFR is because of endotheliosis and primarily through reduction in the ultra filtration coefficient as opposed to diminished plasma flow. Mild forms have been observed in 30\% patients with pregnancy-induced hypertension without proteinuria $[80,81]$. A recent study found 5 of 12 control subjects with trace endotheliosis. Limited endotheliosis have also been reported occasionally in association with other disorders [82]. Studies revealed that women with PE history have elevated blood pressure, endothelial dysfunction, weight gain and other signs of adverse cardiovascular risk profile both before and after preeclaamptic pregnancy $[83,84]$. No study has suggested that preeclampsia itself has negative effect on blood pressure and microalbuminuria although studies suggest its effect on worsening cardiovascular risk profile after pregnancy in women with PE. It is also noted that extensive glomerular changes can also be resolved postpartum. The fact that $20-40 \%$ of women have microalbuminuria after preeclamptic pregnancy is in confusion for a permanent glomerular damage in a great proportion of these women. Several investigators argue that proteinuria itself causes continued renal dysfunction via increased interstitial inflammation, and same for microalbuminuria [58].

\section{Conclusion}

Preeclampsia is a systemic disorder characterized by maternal endothelial dysfunction. Adequate screening, monitoring and routine check-up during and after pregnancy may prevent worsening the maternal and fetus condition. Previous history of PE helps with the assessment of early diagnosis and the risk of CVD and CKD. This review summarizes the systemic endothelial dysfunction, risk factors, pathogenesis, pathophysiology and renal effects of PE.

\section{Acknowledgement}

The authors are thankful to be supported by the Research
Center of the "Center for Female Scientific and Medical Colleges", Deanship of Scientific Research, King Saud University, Riyadh.

\section{References}

1. Stillman IE, Karumanchi SA. The glomerular injury of preeclampsia. J Am Soc Nephrol. 2007;18(8):22812284.

2. Saftlas AF, Olson DR, Franks AL, Atrash HK, Pokras R. Epidemiology of preeclampsia and eclampsia in the United States, 1979-1986. Am J Obstet Gynecol. 1990;163(2):460-465.

3. Sibai BM, Gordon T, Thom E, Caritis SN, Klebanoff M, McNellis D, Paul RH. Risk factors for preeclampsia in healthy nulliparous women: a prospective multicenter study. The National Institute of Child Health and Human Development Network of Maternal-Fetal Medicine Units. Am J Obstet Gynecol. 1995;172(2 Pt 1):642-648.

4. Zhang J, Meikle S, Trumble A. Severe maternal morbidity associated with hypertensive disorders in pregnancy in the United States. Hypertens Pregnancy. 2003;22(2):203-212.

5. Walker JJ. Pre-eclampsia. Lancet. 2000;356(9237):12601265.

6. Roberts JM, Cooper DW. Pathogenesis and genetics of pre-eclampsia. Lancet. 2001;357(9249):53-56.

7. Page EW. The relation between hydatid moles, relative ischemia of the gravid uterus and the placental origin of eclampsia. Am J Obstet Gynecol. 1939;37:291-293.

8. Roberts JM, Taylor RN, Musci TJ, Rodgers GM, Hubel CA, McLaughlin MK. Preeclampsia: an endothelial cell disorder. Am J Obstet Gynecol. 1989;161(5):1200-1204.

9. Roberts JM. Preeclampsia: what we know and what we do not know. Semin Perinatol. 2000;24(1):24-28.

10. Lafayette RA, Druzin M, Sibley R, Derby G, Malik T, Huie P, Polhemus C, et al. Nature of glomerular dysfunction in pre-eclampsia. Kidney Int. 1998;54(4):12401249.

11. Duckitt K, Harrington D. Risk factors for pre-eclampsia at antenatal booking: systematic review of controlled studies. BMJ. 2005;330(7491):565.

12. Ananth S, Maynard SE, Stillmann IE. Preeclampsia: A renal prespective. Kid Inter. 2005;67:2101-2113.

13. Redman CW, Sargent IL. Latest advances in understanding preeclampsia. Science. 2005;308(5728):1592-1594.

14. Sibai B, Dekker G, Kupferminc M. Pre-eclampsia. Lancet. 2005;365(9461):785-799.

15. Lachmeijer AM, Arngrimsson R, Bastiaans EJ, Frigge ML, Pals G, Sigurdardottir S, Stefansson H, et al. A genome-wide scan for preeclampsia in the Netherlands. Eur J Hum Genet. 2001;9(10):758-764.

16. Keyes LE, Armaza JF, Niermeyer S, Vargas E, Young 
DA, Moore LG. Intrauterine growth restriction, preeclampsia, and intrauterine mortality at high altitude in Bolivia. Pediatr Res. 2003;54(1):20-25.

17. Chesley LC. History and epidemiology of preeclampsiaeclampsia. Clin Obstet Gynecol. 1984;27(4):801-820.

18. Saito S, Shiozaki A, Nakashima A, Sakai M, Sasaki Y. The role of the immune system in preeclampsia. Mol Aspects Med. 2007;28(2):192-209.

19. Sargent IL, Borzychowski AM, Redman CW. Immunoregulation in normal pregnancy and pre-eclampsia: an overview. Reprod Biomed Online. 2006;13(5):680-686.

20. Catov JM, Ness RB, Kip KE, Olsen J. Risk of early or severe pre-eclampsia related to pre-existing conditions. Int J Epidemiol. 2007;36(2):412-419.

21. Fischer MJ, Lehnerz SD, Hebert JR, Parikh CR. Kidney disease is an independent risk factor for adverse fetal and maternal outcomes in pregnancy. Am J Kidney Dis. 2004;43(3):415-423

22. Fink JC, Schwartz SM, Benedetti TJ, Stehman-Breen $\mathrm{CO}$. Increased risk of adverse maternal and infant outcomes among women with renal disease. Paediatr Perinat Epidemiol. 1998;12(3):277-287.

23. McDonald SD, Han Z, Walsh MW, Gerstein HC, Devereaux PJ. Kidney disease after preeclampsia: a systematic review and meta-analysis. Am J Kidney Dis. 2010;55(6):1026-1039.

24. Lim KH, Friedman SA, Ecker JL, Kao L, Kilpatrick SJ. The clinical utility of serum uric acid measurements in hypertensive diseases of pregnancy. Am J Obstet Gynecol. 1998;178(5):1067-1071.

25. Bujold E, Romero R, Chaiworapongsa T, Kim YM, Kim GJ, Kim MR, Espinoza J, et al. Evidence supporting that the excess of the sVEGFR-1 concentration in maternal plasma in preeclampsia has a uterine origin. J Matern Fetal Neonatal Med. 2005;18(1):9-16.

26. Chaiworapongsa T, Romero R, Kim YM, Kim GJ, Kim MR, Espinoza J, Bujold E, et al. Plasma soluble vascular endothelial growth factor receptor-1 concentration is elevated prior to the clinical diagnosis of pre-eclampsia. J Matern Fetal Neonatal Med. 2005;17(1):3-18.

27. Romero R, Nien JK, Espinoza J, Todem D, Fu W, Chung $\mathrm{H}$, Kusanovic JP, et al. A longitudinal study of angiogenic (placental growth factor) and anti-angiogenic (soluble endoglin and soluble vascular endothelial growth factor receptor-1) factors in normal pregnancy and patients destined to develop preeclampsia and deliver a small for gestational age neonate. J Matern Fetal Neonatal Med. 2008;21(1):9-23.

28. Gu Y, Lewis DF, Wang Y. Placental productions and expressions of soluble endoglin, soluble fms-like tyrosine kinase receptor-1, and placental growth factor in normal and preeclamptic pregnancies. J Clin Endocrinol Metab. 2008;93(1):260-266.

29. Woolcock J, Hennessy A, Xu B, Thornton C, Tooher
J, Makris A, Ogle R. Soluble Flt-1 as a diagnostic marker of pre-eclampsia. Aust N Z J Obstet Gynaecol. 2008;48(1):64-70.

30. Keck PJ, Hauser SD, Krivi G, Sanzo K, Warren T, Feder J, Connolly DT. Vascular permeability factor, an endothelial cell mitogen related to PDGF. Science. 1989;246(4935):1309-1312.

31. Clauss M, Weich H, Breier G, Knies U, Rockl W, Waltenberger J, Risau W. The vascular endothelial growth factor receptor Flt-1 mediates biological activities. Implications for a functional role of placenta growth factor in monocyte activation and chemotaxis. J Biol Chem. 1996;271(30):17629-17634.

32. Chappell JC, Taylor SM, Ferrara N, Bautch VL. Local guidance of emerging vessel sprouts requires soluble Flt-1. Dev Cell. 2009;17(3):377-386.

33. Ferrara N, Carver-Moore K, Chen H, Dowd M, Lu L, O'Shea KS, Powell-Braxton L, et al. Heterozygous embryonic lethality induced by targeted inactivation of the VEGF gene. Nature. 1996;380(6573):439-442.

34. Maharaj AS, Saint-Geniez M, Maldonado AE, D'Amore PA. Vascular endothelial growth factor localization in the adult. Am J Pathol. 2006;168(2):639-648.

35. Esser S, Wolburg K, Wolburg H, Breier G, Kurzchalia T, Risau W. Vascular endothelial growth factor induces endothelial fenestrations in vitro. J Cell Biol. 1998;140(4):947-959.

36. Ku DD, Zaleski JK, Liu S, Brock TA. Vascular endothelial growth factor induces EDRF-dependent relaxation in coronary arteries. Am J Physiol. 1993;265(2 Pt 2):H586-592.

37. Luttun A, Tjwa M, Moons L, Wu Y, Angelillo-Scherrer A, Liao F, Nagy JA, et al. Revascularization of ischemic tissues by PIGF treatment, and inhibition of tumor angiogenesis, arthritis and atherosclerosis by anti-Flt1. Nat Med. 2002;8(8):831-840.

38. Autiero M, Waltenberger J, Communi D, Kranz A, Moons L, Lambrechts D, Kroll J, et al. Role of PlGF in the intra- and intermolecular cross talk between the VEGF receptors Flt1 and Flk1. Nat Med. 2003;9(7):936943.

39. Cackovic M, Buhimschi CS, Zhao G, Funai EF, Norwitz ER, Kuczynski E, Lockwood CJ, et al. Fractional excretion of tumor necrosis factor-alpha in women with severe preeclampsia. Obstet Gynecol. 2008;112(1):93100.

40. Sandrim VC, Palei AC, Metzger IF, Gomes VA, Cavalli RC, Tanus-Santos JE. Nitric oxide formation is inversely related to serum levels of antiangiogenic factors soluble fms-like tyrosine kinase- 1 and soluble endogline in preeclampsia. Hypertension. 2008;52(2):402-407.

41. Myers J, Mires G, Macleod M, Baker P. In preeclampsia, the circulating factors capable of altering in vitro endothelial function precede clinical disease. Hypertension. 
2005;45(2):258-263.

42. Clark DE, Smith SK, He Y, Day KA, Licence DR, Corps AN, Lammoglia R, et al. A vascular endothelial growth factor antagonist is produced by the human placenta and released into the maternal circulation. Biol Reprod. 1998;59(6):1540-1548.

43. Maynard SE, Min JY, Merchan J, Lim KH, Li J, Mondal S, Libermann TA, et al. Excess placental soluble fmslike tyrosine kinase 1 (sFlt1) may contribute to endothelial dysfunction, hypertension, and proteinuria in preeclampsia. J Clin Invest. 2003;111(5):649-658.

44. Venkatesha S, Toporsian M, Lam C, Hanai J, Mammoto T, Kim YM, Bdolah Y, et al. Soluble endoglin contributes to the pathogenesis of preeclampsia. Nat Med. 2006;12(6):642-649.

45. Maharaj AS, Walshe TE, Saint-Geniez M, Venkatesha S, Maldonado AE, Himes NC, Matharu KS, et al. VEGF and TGF-beta are required for the maintenance of the choroid plexus and ependyma. J Exp Med. 2008;205(2):491-501.

46. Wallenburg HCS. Hemodynamics of hypertensive pregnancy, in Handbook of Hypertension, 1988, edited by Rubin PC, New York, Elsevier Science, pp 66-101.

47. Victor R, Mark A. The sympathetic nervous system in human hypertension, in Hypertension: Pathophysiology, Diagnosis, and Management, 1995, edited by Laragh J, Brenner B, 2nd ed., New York, NY, Raven Press, pp 865-887.

48. Gant NF, Daley GL, Chand S, Whalley PJ, MacDonald PC. A study of angiotensin II pressor response throughout primigravid pregnancy. J Clin Invest. 1973;52(11):26822689.

49. Redman CW. Maternal plasma volume and disorders of pregnancy. Br Med J (Clin Res Ed). 1984;288(6422):955956.

50. Tapia HR, Johnson CE, Strong CG. Renin-angiotensin system in normal and in hypertensive disease of pregnancy. Lancet. 1972;2(7782):847-850.

51. August P, Lenz T, Ales KL, Druzin ML, Edersheim TG, Hutson JM, Muller FB, et al. Longitudinal study of the renin-angiotensin-aldosterone system in hypertensive pregnant women: deviations related to the development of superimposed preeclampsia. Am J Obstet Gynecol. 1990;163(5 Pt 1):1612-1621.

52. Okuno S, Hamada H, Yasuoka M, Watanabe H, Fujiki Y, Yamada N, Sohda S, et al. Brain natriuretic peptide (BNP) and cyclic guanosine monophosphate (cGMP) levels in normal pregnancy and preeclampsia. J Obstet Gynaecol Res. 1999;25(6):407-410.

53. Agatisa PK, Ness RB, Roberts JM, Costantino JP, Kuller LH, McLaughlin MK. Impairment of endothelial function in women with a history of preeclampsia: an indicator of cardiovascular risk. Am J Physiol Heart Circ Physiol. 2004;286(4):H1389-1393.
54. Chambers JC, Fusi L, Malik IS, Haskard DO, De Swiet M, Kooner JS. Association of maternal endothelial dysfunction with preeclampsia. JAMA. 2001;285(12):16071612 .

55. Sibai BM. Intergenerational factors: a missing link for preeclampsia, fetal growth restriction, and cardiovascular disease? Hypertension. 2008;51(4):993-994.

56. Wolf M, Hubel CA, Lam C, Sampson M, Ecker JL, Ness RB, Rajakumar A, et al. Preeclampsia and future cardiovascular disease: potential role of altered angiogenesis and insulin resistance. J Clin Endocrinol Metab. 2004;89(12):6239-6243.

57. Lykke JA, Langhoff-Roos J, Sibai BM, Funai EF, Triche EW, Paidas MJ. Hypertensive pregnancy disorders and subsequent cardiovascular morbidity and type 2 diabetes mellitus in the mother. Hypertension. 2009;53(6):944951.

58. Irgens HU, Reisaeter L, Irgens LM, Lie RT. Long term mortality of mothers and fathers after pre-eclampsia: population based cohort study. BMJ. 2001;323(7323):12131217.

59. Berends AL, de Groot CJ, Sijbrands EJ, Sie MP, Benneheij SH, Pal R, Heydanus R, et al. Shared constitutional risks for maternal vascular-related pregnancy complications and future cardiovascular disease. Hypertension. 2008;51(4):1034-1041.

60. James PR, Nelson-Piercy C. Management of hypertension before, during, and after pregnancy. Heart. 2004;90(12):1499-1504.

61. Magnussen EB, Vatten LJ, Lund-Nilsen TI, Salvesen KA, Davey Smith G, Romundstad PR. Prepregnancy cardiovascular risk factors as predictors of pre-eclampsia: population based cohort study. BMJ. 2007;335(7627):978.

62. Thadhani R, Solomon CG. Preeclampsia--a glimpse into the future? N Engl J Med. 2008;359(8):858-860.

63. Valdes G, Quezada F, Marchant E, von Schultzendorff A, Moran S, Padilla O, Martinez A. Association of remote hypertension in pregnancy with coronary artery disease: a case-control study. Hypertension. 2009;53(4):733-738.

64. Wilson BJ, Watson MS, Prescott GJ, Sunderland S, Campbell DM, Hannaford P, Smith WC. Hypertensive diseases of pregnancy and risk of hypertension and stroke in later life: results from cohort study. BMJ. 2003;326(7394):845.

65. Kajantie E, Eriksson JG, Osmond C, Thornburg K, Barker DJ. Pre-eclampsia is associated with increased risk of stroke in the adult offspring: the Helsinki birth cohort study. Stroke. 2009;40(4):1176-1180.

66. Slemmons J, Bogert L. The uric acid content of maternal and fetal blood. J Biol Chem. 1971;32:63-69.

67. Martin JN, Jr., May WL, Magann EF, Terrone DA, Rinehart BK, Blake PG. Early risk assessment of severe preeclampsia: admission battery of symptoms and laboratory tests to predict likelihood of subsequent significant 
maternal morbidity. Am J Obstet Gynecol. 1999;180(6 Pt 1):1407-1414.

68. Sagen N, Haram K, Nilsen ST. Serum urate as a predictor of fetal outcome in severe pre-eclampsia. Acta Obstet Gynecol Scand. 1984;63(1):71-75.

69. Schaffer N, Dill L, Cadden J. Uric acid clearance in normal pregnancy and preeclampsia. J Clin Invest. 2003;22:201-206.

70. Chaiworapongsa T, Romero R, Yoshimatsu J, Espinoza J, Kim YM, Park K, Kalache K, et al. Soluble adhesion molecule profile in normal pregnancy and pre-eclampsia. J Matern Fetal Neonatal Med. 2002;12(1):19-27.

71. Schwartz RB, Feske SK, Polak JF, DeGirolami U, Iaia A, Beckner KM, Bravo SM, et al. Preeclampsia-eclampsia: clinical and neuroradiographic correlates and insights into the pathogenesis of hypertensive encephalopathy. Radiology. 2000;217(2):371-376.

72. Rule AD, Larson TS, Bergstralh EJ, Slezak JM, Jacobsen SJ, Cosio FG. Using serum creatinine to estimate glomerular filtration rate: accuracy in good health and in chronic kidney disease. Ann Intern Med. 2004;141(12):929-937.

73. Eknoyan G, Hostetter T, Bakris GL, Hebert L, Levey AS, Parving HH, Steffes MW, et al. Proteinuria and other markers of chronic kidney disease: a position statement of the national kidney foundation (NKF) and the national institute of diabetes and digestive and kidney diseases (NIDDK). Am J Kidney Dis. 2003;42(4):617-622.

74. Spargo BH, Lichtig C, Luger AM, Katz AI, Lindheimer MD. The renal lesion in preeclampsia. Perspect Nephrol Hypertens. 1976;5:129-137.

75. Kirsztajn GM. Determinacaourinaria de proteinas de baixo peso molecular. Diagnostico laboratorial emne- frologia. Sao Paulo: Sarvier. 2009;64-74.

76. Thais AF, Gianna M, Nelson S. Preeclamsia (marker of chronic kidney disease): from genesis to future risk. J Bras Nephrol. 2012;34(1):87-93.

77. Garovic VD, Wagner SJ, Turner ST, Rosenthal DW, Watson WJ, Brost BC, Rose CH, et al. Urinary podocyte excretion as a marker for preeclampsia. Am J Obstet Gynecol. 2007;196(4):320 e321-327.

78. Karumanchi SA, Maynard SE, Stillman IE, Epstein FH, Sukhatme VP. Preeclampsia: a renal perspective. Kidney Int. 2005;67(6):2101-2113.

79. Gaber LW, Spargo BH, Lindheimer MD. Renal pathology in pre-eclampsia. Baillieres Clin Obstet Gynaecol. 1994;8(2):443-468.

80. Fisher KA, Luger A, Spargo BH, Lindheimer MD. Hypertension in pregnancy: clinical-pathological correlations and remote prognosis. Medicine (Baltimore). 1981;60(4):267-276.

81. Strevens H, Wide-Swensson D, Hansen A, Horn T, Ingemarsson I, Larsen S, Willner J, et al. Glomerular endotheliosis in normal pregnancy and pre-eclampsia. BJOG. 2003;110(9):831-836.

82. Subramanya A, Houghton D, Watnick S. Steroid-responsive idiopathic glomerular capillary endotheliosis: case report and literature review. Am J Kidney Dis. 2005;45(6):1090-1095.

83. Laivuori H, Tikkanen MJ, Ylikorkala O. Hyperinsulinemia 17 years after preeclamptic first pregnancy. J Clin Endocrinol Metab. 1996;81(8):2908-2911.

84. Hubel CA, Snaedal S, Ness RB, Weissfeld LA, Geirsson RT, Roberts JM, Arngrimsson R. Dyslipoproteinaemia in postmenopausal women with a history of eclampsia. BJOG. 2000;107(6):776-784. 